\title{
UM CADERNO, SETE LEITORES
}

\author{
Isabela Braz (UFF) \\ Leonardo de Freitas Bezerra Vilela (UFF) \\ Louise Ribeiro Cruz (UFF) \\ Luís Henrique Gonçalves Vargas (UFF) \\ Maria Lúcia Wiltshire de Oliveira (UFF) \\ Mariana Neto Silva Andrade (UFF) \\ Rita Isadora Pessoa Soares de Lima (UFF)
}

"Procura as palavras a partir das coisas" (GERSÃO, 2013, p. 92), não o contrário. Assim lemos As águas livres de Teolinda Gersão, uma escrita rente à vida, como disse Eduardo Prado Coelho. Livres e vivas, as palavras escorrem claras segundo o ensinamento de Espinosa na epígrafe: "Tudo o que percebemos clara e distintamente é verdadeiro". Sem obedecer a parâmetros fixos de gênero, o livro recupera o fio do (falso) Diário Os Guarda-chuvas cintilantes (publicado em 1984) que se torna, a

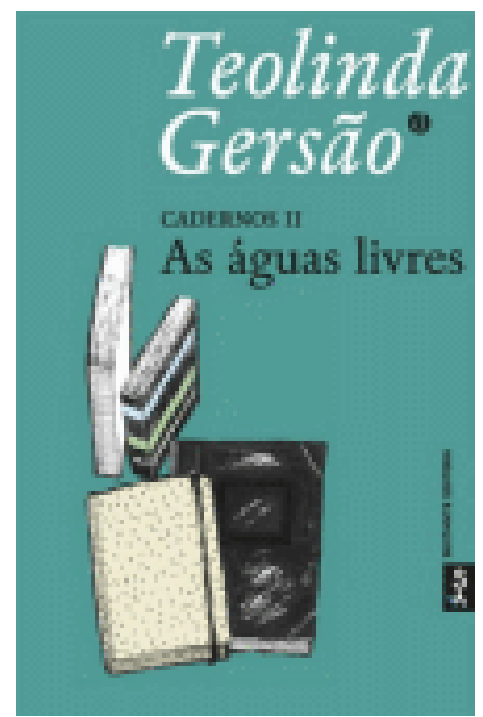
contrapelo, um Caderno I. A estrutura fragmentária do diário é comum às duas obras, mas nesta última a água da escrita jorra com mais liberdade, mesclando memórias a reflexões sobre literatura, arte, cultura portuguesa, vida moderna, ao mesmo tempo em que percorre as ruas num percurso à Cesário Verde. Há sobretudo um olhar sobre a própria escrita e sobre as obras já publicadas da autora que, em primeira pessoa, reflete sobre o processo de alterização, em duplos de si que relativizam o autobiografismo em estrito senso, aproximando-se da autoficção. Ainda que o tecido da prosa se apresente de forma fragmentária, como os antigos hypomnematas de que fala Foucault, há também unidades orgânicas mais longas que poderiam figurar como micronarrativas, contos ou crônicas. 
"Encontro ruas que vão dar a impasses e escadas que acabam de repente. Por vezes sinto-me dentro de um desenho de Escher." (GERSÃO, 2013, p. 73) Efetivamente em A cascata de Escher há uma série de espaços impossíveis ou absurdos que nos levam a acreditar numa outra lógica das águas, em que não podemos apontar um início e um fim específicos: o fluxo se inicia no momento da queda ou na piscina que se forma abaixo dela? A experiência da escrita de si é este fluxo que nunca é o mesmo na manutenção de um diário. $\mathrm{E}$ isso vale também para o sentido que atribuímos a ela, experiência, que precisa ser constantemente atualizada, ou refeita.

Continuo a registrar notas em pequenos cadernos. Como sempre fiz, ao longo dos anos. Datei-as e poderiam corresponder a um calendário, mas relendo-as apercebo-me da impossibilidade de arrumá-las. Apesar das datas resistem a qualquer ordem, insistem em continuar soltas. Posso começar a lê-las pelo fim e pelo meio. Não existe a ponta do novelo. Ou fui eu que a deixei cair, e perdi-a. (GERSÃO, 2013, p. 7)

Já no título da obra entrevemos a metáfora que aponta para a liberdade da escrita enquanto desembocadura líquida, fluida e corrente. A escrita corre sem um destino prévio, com seu leito e afluentes, sem se deter, fazendo-se sem os limites da cronologia como se um calendário impossível fosse a única temporalidade que importa, e o olhar rápido, à distância, constituísse o elo necessário para estabelecer o mosaico, a totalidade que a obra engendra. Não é, portanto, nenhuma surpresa que o uso da metalinguagem seja recorrente aqui. Uma possibilidade interessante ofertada pelo trabalho metalinguístico em Gersão é a de vislumbrar a dobra da escrita, isto é, a dobradura mimética que a linguagem realiza sobre si própria, revelando sua faceta de resistência: a escrita como algo que não desiste, que insiste e tensiona, com caráter de pulsão. Escrever tem algo de urgência, de vício, de compulsão. O "escrever no comboio" de que fala Gersão traz a noção de uma inevitabilidade, mas também de uma precariedade: uma tentativa de estar no mesmo compasso que a escrita e de uma decalagem da qual não se escapa.

$\mathrm{Na}$ fluência destas “águas livres” há remissão a eventos variados da vida da autora, seja em sua trajetória literária, seja em diferentes aspectos de seu convívio social e familiar. A esses fragmentos biografemáticos pertencem referências ao início da prolongada relação interpessoal entre Gersão e Virgílio Ferreira, à publicação de sua segunda obra - Os guarda-chuvas cintilantes -, compreendendo inclusive reflexões sobre a capa do livro, em sua primeira edição adaptada de obra de Vieira da Silva e às observações acerca de outros volumes já publicados, como Paisagem com mulher ao fundo e A casa da cabeça de cavalo. A certa altura, num fragmento trazido do passado, a narradora rende-se a um novo texto, de vontade imperiosa, que atravessa a sua escrita: era um romance em gestação que pedia para vir à lume e que, se não fosse liberado, impediria o livre fluxo tanto de uma quanto de outra escrita: "se tentar de outro modo, nenhum dos livros 
avança" (GERSÃO, 2013, p. 121). O novo volume, não nomeado, era $O$ cavalo de sol, texto que começa "a passo, portanto numa cadência vagarosa", e que segue para o trote, o galope e enfim o salto, "ponto de chegada e o fim da narrativa” (GERSÃO, 2013, p. 121).

Há, também, apontamentos da autora quanto à nova casa, para a qual ela e sua família se mudam, e a consequente abordagem de assuntos de cunho íntimo, incluindo uma referência às suas filhas que "tornaram-se autônomas" e as quais, portanto, já não se pode entreter com "histórias de esquilos e girafas" (GERSÃO, 2013, p. 88) - aqui, outra insinuada alusão a Guarda-chuvas cintilantes. Esses biografemas, para além de apontarem em direção a pontos de reflexão metalinguística, desvendando os percursos pelos quais Gersão avalia a ficção por si própria engendrada, também ajudam a, de certa forma, tornar o leitor alguém mais íntimo da voz autoral, que não se pretende única, uma vez que seu discurso é entrecortado por diferentes dicções, narrativas breves e fugidias, mas que se abre paulatinamente para o convívio próximo com o leitor posicionado no portal do texto.

Através de flashes de cenas cotidianas, a autora parece buscar uma relação entre a vida urbana e a escrita pessoal do eu. Assume sua condição baudelairiana de flâneur percorrendo caminhos e celebrando a vida moderna. Suas anotações são como retalhos de momentos formadores de um caleidoscópio que, em vez de confundir, é, pelo contrário, um retrato da cultura portuguesa. Quando fala, por exemplo, da velha de farrapos abanando o vapor das castanhas assadas, cria imagens sinestésicas elucidativas da chegada do outono. Os fragmentos são capazes de mostrar ao leitor uma forma diferenciada de experimentar sensações, momentos e ideias.

Ao revisitar o passado, a autora traz o seu ser infante que se encantou diante dos variados tipos humanos portugueses em vias de extinção, com um olhar antropológico que preserva a "loja de lenha" das antigas casas rurais, assim como os vendedores da cidade, como o "farrapeiro", a "peixeira", o "leiteiro", o "padeiro", o "latoeiro", o "amola-tesouras" e o "velho da areia" a anunciar a areia para arear panelas e tachos. Além das figuras singulares de domésticas, como Ifigênia, de resto bem recorrentes em seus romances, há uma quase-crônica sobre um certo colecionador que reflete sobre a passagem do tempo. O que é um colecionador? Talvez alguém que guarde a coisa "para memória futura, como se as metesse numa cápsula do tempo" (GERSÃO, 2013, p. 50). E por isso, "tinha uma predileção por relógios" (GERSÃO, 2013, p. 52)

A sua escrita retoma, ainda, a crítica a um Portugal velho que ainda continua a existir no campo e nas cidades. Uma sociedade orgulhosa de sua própria melancolia, uma cultura que ao longo das gerações produziu um certo "culto da tristeza". Um "culto" emblemático como o luto perpétuo das viúvas. A cultura portuguesa parece desconfiar da alegria. Existiria, então, um "vírus da tristeza"? A Igreja com suas quaresmas, a maledicência 
das mulheres, a desconfiança em relação ao corpo e à vida e a permanência do marialvismo parecem indicar que sim. A essa sociedade "desconfiada", no entanto, Teolinda Gersão contrapõe a alegria e a leveza de uma escrita iluminada pela leitura de Espinosa. Sob esse aspecto, podemos, então, compreender o papel da narradora no combate a uma visão reduzida do que se imagina ser a realidade: Um mundo produtor de "zombies que tentam sem conseguir preencher o vazio das suas vidas" (GERSÃO, 2013, p .95).

Portugal é descrito como um país de contrastes. Não é o país uniforme que a herança cristã pretendeu um dia criar. "Tão próximos de nós, os muçulmanos, há tantos séculos. Tanta coisa nos divide e aproxima" (GERSÃO, 2013, p. 160). Realça-se, assim, a influência sempre presente da cultura árabe em um país "curioso, em que se andam dez ou vinte quilômetros e a paisagem é outra, há uma diversidade enorme de paisagens naturais e humanas" (GERSÃO, 2013, p. 160). Essa diversidade, por sua vez, não elimina o atraso. Com efeito, tudo parece "ridiculamente pequeno, como num país de brinquedos". Um país habitado pelos fantasmas "de um mundo desparecido há mais de um século” (GERSÃO, 2013, p. 104)

O livro é constituído por fragmentos de vários Cadernos, crônicas, contos e micronarrativas com individualidade própria e sem ordem aparente. Os textos urdem-se num conjunto híbrido que se situa no entre-lugar do pensamento autoral e do impulso escritural. O leitor deve entendê-los como unidades orgânicas não propriamente fragmentárias que, a despeito de independentes, encontram-se congênita e complementarmente interconectadas. Tais unidades encaixam-se como um puzzle que pode ser interminavelmente montado e remontado na mente do leitor. $\mathrm{E}$ a leitura de cada unidade orgânica é livre e flui tal como a água que, de modo ininterrupto e irrefreável, escapa entre os dedos de nossas mãos. "O Sentido não se prende, é algo em trânsito” (GERSÃO, 2013, p. 157). Após ler a obra, o leitor sai revigorado com as experiências sensoriais e estéticas, movido por um fazer literário que estimula a "potência de afetos", algo que alcança o ser, em significativas abrangência e verticalidade. Tal organização evidencia exercícios sutis de atenção acerca do mundo, que conduzem o leitor a amplos e variados territórios - inclusive o onírico -, geografias diversas, simultaneidade de espaços e tempos.

Para os sete leitores que assinam esta resenha, a obra de Gersão funciona, de fato, como coletânea de fragmentos variados, eternização de instantes - ou, nas palavras da própria, "momentos de gozo, registros curtos do imediato [...], pequenas fugas” (GERSÃO, 2013, p. 155). Nesse caleidoscópio há prazer e fruição, que escorrem no interstício entre autor e leitor e se espraiam em páginas insidiantes. A obra aparece aqui imbuída de um matiz inexorável - ela é o único trajeto possível. Daí a importância da ideia de destino, de percurso, que inclui hiatos e dissensos, rupturas e recomeços, tal como a própria trajetória da água, que segue inabalável, criando seu caminho na mesma medida em que se desvia de obstáculos e rochas, seguindo ora plácida ora abismal. 
O sentido não pré-existe, está sempre por fazer. É, portanto, uma construção. E, como toda construção discursiva (e aqui podemos remeter à etimologia desta palavra, que retoma a ideia de curso das águas), tem os seus problemas, as suas aporias. E é questão de tempo até que essas aporias se acentuem a ponto de se tornarem buracos negros do texto, que engolem todo o sentido que encontrarem. E aí é preciso começar tudo de novo, num moto-perpétuo. Essa talvez seja a motivação de um diário. Ou mesmo de qualquer modalidade de escrita. Em meio a um mundo caótico, impermanente, é preciso assegurar algo, elaborar sentido para seguir em frente. Se a verdade não existe a priori, e essa é grande virada da modernidade, é preciso laboriosamente construí-la.

\section{REFERÊNCIA BIBLIOGRÁFICA}

GERSÃO, Teolinda. As águas livres. Cadernos II. Porto: Editora Sextante, 2013.

Recebido para publicação em 13/05/2014

Aprovado em 27/09/2014 